\title{
The Survival of a President: Alternate History and the Spectre of Vietnam in Stephen
}

\section{King's 11/22/63 ${ }^{1}$}

'We in this country, in this generation, are ... the watchmen of the walls of world freedom'

— John F. Kennedy, remarks prepared for delivery at the Trade Mart in Dallas, Texas, 22 November 1963

The assassination of John F. Kennedy has haunted American cultural history for more than half a century, being called by Marita Sturken, among others, 'the most pivotal moment in late twentieth-century American history' (Sturken 1997: 71), a moment that Stephen King explores in his 2012 novel, 11/22/63. A pivotal moment such as the Kennedy assassination centres on an event that shapes subsequent events in its wake. Some monumental moments have changed the world as a whole, such as the terrorist attacks of 11 September 2001 in the United States, or the fall of the Berlin Wall in 1988. Other, more localised, events have affected individuals and communities in a similar way, but do not have the global impact of larger events, such as the assassination of John F. Kennedy, which in retrospect, is fundamental to both American culture and world history, and has become a moment recognised more widely within the world's collective consciousness. It has been written about in fiction, analysed in documentaries, reproduced in film, and even in recreated in videogames.

The intense fixation on the shooting at Dealey Plaza in Dallas on 22 November 1963, which George identifies, is also reflected through its manifold representations in the literary sphere. King's 11/22/63 enters into a literary tradition that spans many years and includes Don DeLillo's Libra (1988) and James Ellroy's American Tabloid (1995) amongst others. 
Subsequent literary appropriations of Kennedy's death have extended beyond historical representations of the figures and events surrounding the assassination. This is achieved by speculating on the prospective consequences of erasing the trauma of the shooting from America's cultural memory and presenting an alternate history in which the president survives the bullet of Lee Harvey Oswald, such as Jeff Greenfield's If Kennedy Lived (2013) or Bryce Zabel's novel Surrounded by Enemies (2015). The assassination, even after more than fifty years, continues to be cited as integral to Anglo-American history in the twentyfirst century, both through re-enactments of the events at Dealey Plaza and alternative histories that change the outcome of the President's journey through Dallas. James Piereson states that the assassination was a shock that the American public 'could never quite get over' (2013: viii) and given the 'unprecedented intensity and immediacy' of the media coverage of the assassination, which 'elicited reactions of grief and sorrow from the vast majority of Americans, regardless of their social status or prior interest in national politics' (Fenn 2017: 64).

Giving extensive consideration to the question of why there has been so much interest in this president's death, Alice L. George suggests that the fascination with Kennedy's assassination 'remains a vivid moment in American cultural history because it ripped through the fabric of America's self-image' (George 2012: 1). She considers this to 'show the lie inherent in Americans' belief that they could accomplish anything', and that 'the assassination bred mistrust, and over time, it became impossible for Americans to believe any simple solution to such a significant occurrence' (George 2012: 1-2). This, she considers, was a momentous event in the contemporary American cultural milieu that has only been rivalled by the terrorist attacks on 9/11. King's use of alternate history in 11/22/63 and the survival of the President within that narrative, allows the reader to examine the Kennedy assassination and its repercussions in detail, both in terms of the conspiracy 
theories that surround the shooting, the ramifications of the President's death, and his hypothetical survival. The reader is thus able to consider whether the ability to change past events should be undertaken, even if they can be, through this pivotal and globally recognised event.

Alternate histories generally have a fundamental premise that 'some event in the past did not occur as we know it did' (Hellekson 2001: 2) and, therefore, the present or future is changed. Karen Hellekson, in her exploration of primarily alternative history science fiction novels, The Alternate History: Refiguring Historical Time cites William Joseph Collins, who describes a taxonomy of alternate histories, that can be divided into four sub-categories: the pure uchronia (which implies an alternative history, without the presence of any other reality); a plural uchronia (which situates the alternative reality alongside that the reader inhabits); infinite presents, or parallel worlds; and time travel alterations (which involves travellers moving from the present to the past to alter events. (Hellekson 2001: 5). This manifests in many time travel novels, including Stephen King's 11/22/63, allowing the narrative to explore the concept of time travel and the implications of its success, whist engaging with one of the most famous events of the $20^{\text {th }}$ Century. King previously has displayed a reluctance to fictionalize his own cultural awakening and confront the spectre of both the Kennedy assassination and the Vietnam War, despite its subtle presence in his prolific catalogue of novels, short stories, and poems.

In his extensive rumination on the horror phenomenon, Danse Macabre (1981), King states an intention to avoid writing fiction temporally located in the 1960s:

(A)11 of that seems, like the pulling of that surgical dressing, very distant to me now almost as if they had happened to another person. But those things did happen; the hate, paranoia and fear on both sides were all too real (King 2006: 186) 
King cites a difficulty in remembering 'in any gut way the fears that came with those boom years' (King 2006: 186). Despite this assertion, when reflecting upon the fears and anxieties that he attributes to the 1960s, King appears predominantly fixated upon the spectre of Vietnam, a suggestion ratified by King's reference to the 'pains associated with coming of age in the decade of napalm and the Nehru jacket' (King 2006: 186). It has been recognised by Sears amongst others, however, that despite King's own denial, there is a 'recurrent motif in King's works and prominent in later novels' that fixates on the 'Gothic death of the paternal and its traumatic or liberatory consequences' such as 'the symbolic death of the American 'father' in the Kennedy Assassination' (Sears 2011: 36). However, the Kennedy assassination casts another significant shadow over King's personal, and America's collective, cultural memory, which King interprets as the catalyst for the Vietnam War. When King finally chooses to break his textual silence and confront the horrors he attributes to the 1960s, through the writing of $11 / 22 / 63$, the causal relationship between the Kennedy assassination and the escalation of the Vietnam War permeates King's text.

In 2012, however, King relented and published 11/22/63, a novel which sees the protagonist, Jake Epping, travelling back in time to prevent the Kennedy assassination. 11/22/63 begins with Jake Epping, an English teacher from Lisbon Falls, and a conversation in an empty booth inside the darkened interior of Al's Diner, opposite the diner's proprietor, Al Templeton. In response to Jake's persistent questions about the supposedly instantaneous manifestation of the symptoms of terminal lung cancer on his expediently aged corpus, $\mathrm{Al}$ discloses that he has recently returned from a "vacation" to 1958 , facilitated by a portal behind the diner's pantry door. His primary objective has been to prevent the assassination of President Kennedy, in order to stop America becoming involved in the Vietnam War and to prevent the loss of more than 58,000 American lives. His chronological crusade curtailed by cancer, Al nominates Jake to act as his surrogate to complete his failed expedition to the past, 
and thereby create a better future. During his enlistment of Jake, $\mathrm{Al}$ champions a distinct chain of causality, beginning with the death of John F. Kennedy, and culminating with Lyndon B. Johnson sending troops into Vietnam. As Al hypothesises: if John [Kennedy] lives in Dallas, Robert [Kennedy] probably doesn't run for president in 1968. The country wouldn't have been ready to replace one Kennedy with another ... or what about Vietnam? Johnson was the one who started all the insane escalation. ... Kennedy might have changed his mind. Johnson and Nixon were incapable of that. Thanks to them we lost almost sixty thousand American soldiers in Nam. The Vietnamese, North and South, lost millions. Is the butcher's bill that high if Kennedy doesn't die in Dallas? (King 2012: 54-5, original emphasis).

The culture of pain and fear which King attributes to the sixties as a consequence of the Vietnam War is illustrated through the construction of Templeton as an alternative site for the trauma of Vietnam: his attempt at repressing the conflict resurfaces and is rewritten on the contours of his decaying body.

King's construction of Kennedy's death as the epicentre from which pain and anxiety emerge in the sixties extends beyond the decaying corpus of Al Templeton. It is also evident in Jake's first tentative exploration of the past-world behind the pantry door of Al's Diner. King's construction of Lisbon Falls, 1958, as an idealised space conforms to Gavriel Rosenfield's reflections on the functions of alternate history in Western popular culture, during which he suggests that '[f]antasy scenarios envision the past as superior to the present and thereby express a sense of dissatisfaction with the way things are today' (Rosenfield 2002: 93). Jake's first experience of sensory stimulation upon standing on the cusp of the temporal shift from 2011 to 1958 is the sulphuric stench of the produce generated by the vast machinery of Worumbo Mills and Weaving. Despite the olfactory blemish on the vaguely 
familiar, yet simultaneously changed, landscape that Jake discovers, his perception of Lisbon Falls, 1958, is initially characterized by his overt displays of nostalgic sentimentality for a world of which he has no cultural memory. Jake's indulgence of nostalgia is particularly prominent in his elated response to the taste of the root beer float he samples as a patron of the seemingly rejuvenated Kennebec Fruit Company: 'I sipped through the foam on top, and was amazed. It was ... full. Tasty all the way through. I don't know how to express it any better than that. This fifty-years-gone world smelled worse than I ever would have expected, but it tasted a hell of a lot better' (King 2012: 34, original emphasis). Despite King's initial sentimental vision of the fifties, however, the severity of Jake's alterations of history through his various ventures into the topography of an America fifty years past ultimately creates a reconfiguration of the present in which the landscape has been transformed into a nuclear wasteland. King's conceptualization of a dystopia that is created as a consequence of Jake's frequent manipulations of temporal logic are noteworthy because it adheres to the other basic scenario that Rosenfield suggests: the nightmare. This is typically presented in alternate history narratives as: 'Nightmare scenarios ...depict the past as inferior to the present and thereby express a sense of contentment with the status quo' (Rosenfield 2002: 93). King's text tellingly transitions from one scenario to the other as a direct consequence of Jake's successful prevention of the Kennedy assassination, albeit by sacrificing the life of his lover, librarian Sadie Dunhill, coding the shooting at Dealey Plaza as a 'precipitous fall from a pristine past' (Merchant 2004: 12), from which there is no recovery, just as in the Christian Bible story of Adam and Eve. In $11 / 22 / 63$, the pristine past that Merchant alludes to is epitomised by various aspects of 1950s American culture, which King presents collectively in a nostalgic vision of Lisbon Falls discontinued in Jake's twenty-first-century America, which becomes a Hell on Earth, literally transforming 'the light of an ordered paradise into a dark, disorderly wasteland' (Merchant 2004: 12). 
King's rendering of his nostalgic vision of 1950s America as tragically unsustainable extends beyond the temporal complexity surrounding Jake's romanticized discovery of the beverages served by the Kennebec Fruit Company to his presentation of the automobile. The car was an emblem of suburbia that was widely celebrated and was an integral component of the values that shaped the domestic values of the United States, because it represented a process of technological refinement. According to Jim Cullen, in his extensive rumination on the American Dream, '[1]iterally and figuratively, the automobile embodied personal mobility, and as such was the perfect complement to the anchorage provided by the privately owned [home]' (Cullen 2003: 150). The collective American glorification of the car as a totem of technological enhancement, recognised by Cullen, is perpetuated in 11/22/63 through King's presentation of Jake's 1954 Ford Sunliner convertible, the vehicle he procures to facilitate his pursuit of Lee Harvey Oswald across America. In the context of a novel fixated on the assassination of John F. Kennedy, Jake's chosen mode of transportation occupies a dual cultural space. Like his sensory portrait of the root beer float he samples at the Kennebec Fruit Company, Jake's perception of the 1954 Ford Sunliner in Bill Titus's car lot is imbued with nostalgia constructed from an absent cultural memory:

I window-shopped my way through Titus's car lot. I was particularly taken by a red '54 Ford convertible - a Sunliner, according to the script below the chrome headlight on the driver's side. It had whitewall tyres and a genuine canvas roof that the cool cats in Dragstrip Girl would have called a ragtop ... I thought the Sunliner was the coolest car I'd ever seen in my life' (King 2012: 114).

Jake's hyperbolized perception of the vehicle confirms the Sunliner's totemic status as a motorized symbol of suburbia, and a technological extension of the ethos that Cullen, citing 
the work of the American historian James Truslow Adams, attributes to the idealised notion of the American Dream.

Jake Epping's gravitation towards the ' 54 Ford Sunliner convertible is not, however, exclusively evocative of Adams's original notion of '[an] American dream of a better, richer, and happier life for all our citizens of every rank, which is the greatest contribution we have made to the thought and welfare of the world' (Adams cited in Cullen 2003: 4). It also elicits darker moments from America's collective cultural memory. The Sunliner is a particularly significant choice of automobile to facilitate Jake Epping's attempt to reconfigure American history in light of its shared cultural heritage with another motorized spectre casting a shadow over America's national history, the Lincoln Continental, a car synonymous with the Kennedy assassination, and part of the Ford family of luxury cars. King's implication of the automobile in the more negative memories from America's history, and a subsequent erosion of the fabric of the American Dream, is an inversion of Adams's national ethos. King challenges Adams's presentation of the automobile as an emblem of personal mobility in 11/22/63. Despite its initial, nostalgic representation Ford's connection to the Kennedy assassination renders it an emblem of automotive horror, a reprisal of a motif explored by King through the publication of Christine (1983). In Christine, King features American literary horror's most prominent exemplar of a vehicular totem, which embodies an inversion of aspirational ownership and possession, facilitated by a fulfilment of the American Dream.

Originally, Christine, King's eponymous 1959 Plymouth Fury in his 1983 novel, inspires the irrational passion for the automobile, recognized in American culture by Cullen, in another owner, quintessential teenage geek Arnie Cunningham. As Linda C. Badley states in her essay, "Love and Death in the American Car: Stephen King's Auto-Erotic Horror" (1987), Arnie's love for his new ride is presented in accordance with Cullen's verdict concerning the car's value as a symbol of American suburbia. ${ }^{2}$ Moreover, it is an aspirational 
fantasy of heightened mobility, and a welcome liberation from the stationary environment of the domestic sphere:

As temptress, [Christine] offers Arnie, in fairy-tale succession, the charms of freedom, success, power and love. These come in forms that wimpy teenagers can best appreciate: a mobile home away from his over-protective parents, a cure for acne, vengeance, and a girl, Libertyville High's best looking one, Leigh Cabot (Badley 1987: 86).

As Badley subsequently acknowledges, however, Christine demands reciprocity from Arnie in exchange for her fulfilment of his adolescent fantasies: 'Like Mephistopheles, the car makes Arnie attractive but exacts a price: marriage until death, absolute fidelity - in short, his soul' (Badley 1987: 86). Almost three decades after the publication of Christine, her malevolent presence continues to cast a dark shadow over King's fiction in 11/22/63:

There was ... a two-tone Plymouth Fury. The moon was sliding in and of thin clouds and it wasn't possible to make out the colour of the car's lower half by that stutter light, but I was pretty sure I knew what it was anyway ... Yes, the car was a Fury and yes, it was white over red'

(King 2012: 485).

Christine's reappearance after a thirty-year hiatus perpetuates her implication in the darker aspects of American suburbia by revealing the antagonistic figure of John Clayton, Sadie's estranged husband, as an alternative custodian. This is particularly notable in light of Christine's inaugural appearance in King's alternate history directly prefacing Clayton's deliberate disfigurement of Sadie's face. Additionally, it marks another instance, in King's novel, of a harmonization of the multiple temporal strings that $\mathrm{Al}$ and Jake create in their various exploratory excursions into the rabbit-hole, simultaneously facilitating a drawing together of multiple texts from King's canon. 
As well as self referentially coding 11/22/63 within his own oeuvre, King uses the reappearance of the Plymouth Fury to consider the role of his own nostalgia, something he did in Christine; as Rebecca Janicker explains in The Literary Haunted House, stating that in Christine 'the haunting' of the car 'is not concerned with the past of the novel's narrator-the 1970s - but rather with that of the author — the 1950s' (Janicker 2015: 129). Janicker goes on to explain that Christine 'is a striking visual reminder' of the 'supposedly golden age' (Janicker 2015: 130) of the 1950s, creating something John Sears considers to be 'a kind of 'time machine' transporting Arnie back to the 1950s' (Sears 2011: 94). In 11/22/63, the bubble replaces the car as the method of time travel, but its presence reminds the reader of the nostalgia for the 1950s that is found in King's work, and more widely in American culture.

As well as using his own texts to draw attention to the time frame that $11 / 22 / 63$ occurs in, King repeatedly refers to time as being 'obdurate' (King 2012: 205, 237, 372, 640, 722), stubbornly resistant to the changes that Jake is attempting to implement in what he refers to as 'the land of ago'(King 2012: 443, 488, 616, 619, 700), and intimates that time has autonomous agency. Many counterfactual narratives rest on the premise that a time traveller does something that changes the course of history and the resultant world is then different from the actual world we live in. This adheres to Rosenfeld's understanding of the fantasy and nightmare scenarios. In this novel, King invokes what we are pioneering as 'the Kennedy paradox', a historically specific variation of the grandfather paradox in which a protagonist travels back in time to prevent Oswald murdering Kennedy. The concept of the grandfather paradox has an established cultural lineage, originating in the 1930s and illustrated by the publication of Nathaniel Schachner's Ancestral Voices (1933). It has also been subject to a significant level of critical scrutiny. In Time Machines: Time Travel in Physics, Metaphysics and Science Fiction (1999), Paul J. Nehin cites the grandfather paradox as, 'the classic change-the-past paradox ... which poses the question of what happens if an assassin goes 
back in time and murders his grandfather before his (the time-travelling murderer's) own father is born. If the father is never born, then neither can be the assassin - so how can he go back in the first place to murder his grandfather!?' (Nehin 1999: 48). The paradox is predicated on two contradictory trajectories: firstly, that the past influences the future, and, secondly, that the future influences the same past that created it. $11 / 22 / 63$, like other narratives that use this temporal movement, does so to threaten the fabric of normative reality: the linear, unilateral progression of time. Saving Kennedy thereby creates a variant of the grandfather paradox; expanding its familial links to include American national identity, with Al's ambition being to prevent American involvement in the Vietnam War. This structure allows King to present time as an active participant in the narrative, with a sentience that aims to prevent Jake's changes from altering the future.

In $11 / 22 / 63$, time is given cognisance. King's repeated referrals to time being stubbornly resistant to the changes that Jake is attempting to implement endow it with the ability to $d o$, rather than just exist. Various counterfactual narratives rest on the premise that a time traveller enacts something that changes the course of history and, consequently, the world departs from the recognised trajectory of historical narratives. King's novel enters into this dialogue and attempts to shed light on the concepts of causality-the butterfly effect, where every action has a reaction, especially across time. King uses this structure to question the veracity of whether saving Kennedy, and thereby preventing the Vietnam War, represents the most prudent course of action, with time actively trying to prevent Jake from succeeding in changing history. The novel begins with the supposition that preventing the assassination of President Kennedy would be positive and, initially, Jake's changes do not have strong repercussions - there is no apparent butterfly effect, prompting him to accept Al's request that he save Kennedy. 
King does not only endow time with cognisance, he also bestows a sentience upon it that facilitates the prevention of changes taking place on the 'original' timeline. This is rendered explicit in the television adaptation of the novel. Jake, played by James Franco, attempts to make contact with his future father upon arrival in the past. As he dials the number in a telephone booth, the lights begin to flash, and the telephone emits a whining noise as it is answered. Jake leaves the booth, and as he turns to reattempt the call, a car loses control and crashes into the booth, spilling its occupant from the now burning vehicle. Jake rushes to the apparently dead driver, who opens their eyes to tell him 'you should not be here' ('The Rabbit Hole' 2016). His actions, trying to make contact with his future father, cause time to take direct action to prevent him from succeeding. This is a message repeated throughout the series, especially as Jake facilitates progressively more significant alterations to America's national history, culminating in his attempt to accomplish his ultimate objective: preventing John F. Kennedy's assassination and, consequently, the escalation of the conflict in Vietnam.

The coding of the prevention of the Vietnam War as the primary objective of Jake's journey into the past is particularly in Stephen King's novel, 11/22/63; an objective which Jake seeks to fulfil by enabling Kennedy's survival in Dallas. There are more figures whose lives are impacted by Jake's presence and time can be seen to actively attempt to prevent the changes from occurring in different ways. In King's novel, one of the first major instances of this is Jake's various attempts to save the Dunning family from being murdered. Jake knows Harry Dunning in the twenty-first century and knows that Harry's mother and his siblings were murdered by their father, Frank, on Halloween night 1958. Jake therefore chooses to intervene this as a method of judging whether it is possible to change the future. On the day of the murder, Jake is struck by violent sickness. For the duration of Jake's sufferance of this temporary physical affliction, he repeatedly thinks 'the past does not want to be changed. 
The past is obdurate' (King 2012: 164). Here, through the graphic depictions of Jake's sickness, King make explicit time's determination to prevent Jake implementing the changes he wants to introduce into American culture's temporal linearity. Despite the sickness Jake suffers, however, he ultimately saves the Dunning's from their fate, and returns to the present, where there appears to be no ill effects to the timeline.

Jake's pre-existing knowledge of specific, pivotal moments of the Dunning's familial history contained within the microcosm of American suburbia, symbolized by the Dunning residence on Wyemore Road, Lisbon Falls, means that altering that history functions as the English teacher's litmus test for the mechanics of the rabbit-hole. It also renders Jake a quasiprophetic figure, regarded by Harry as a guardian angel, despite still failing to prevent the death of his brother, Arthur, affectionately referred to as 'Tugga'. Jake's success in salvaging the lives of the rest of the Dunning family, however, also reveals that his prophetic aura has restrictions. Upon returning to 2011, a telephone conversation between Jake and Harry's sister Ellen, miraculously saved by Jake's overwrite of the Dunning's family history simultaneously reveals the confines of Jake's celestial aura:

"I took [Harry] to the airport after he got his orders and his leave was over. He was going to Nam, and I told him to watch his ass. He said, "Don't worry, Sis, I've got a guardian angel to watch out for me, remember?" So where were you on the sixth of February in 1968, Mr Angel? Where were you when my brother died at Khe Sanh?" (King 2012: 212-3).

The telephonic exchange between Jake and Ellen threatens Jake's adherence to a culturally constructed archetype of heroic masculinity. Furthermore, it confirms Vietnam, and not the Kennedy assassination, as the spectre pervading American culture that King fixates upon for the duration of $11 / 22 / 63$. 
King's rendering of Jake as a failed guardian angel is notable for its dual functionality. It positions Jake Epping as emblematic of a threatened contemporary masculine subjectivity that scholars such as Brian Baker have recognized as increasingly prominent in cultural representations of men since the turn of the twenty-first century (Baker 2015: 1). Furthermore, it demonstrates King's awareness of an apparent fixation on ethereal custodians in contemporary America, as 11/22/63 functions as a textual totem of Mark Edmundson's assertion that, 'Angels, for a while, were everywhere in America' (Edmundson 1997: 79). Edmundson subsequently suggests that the appeal of the angel, as a spectral and cultural figuration, is manifest in an assumption that it provides protection and relief from an American culture saturated by the Gothic:

An angel is nearly the diametrical opposite of a Gothic villain ... Our current angels are pure good, completely clean, unambiguously on our side ... if you're used to Gothic villains - to pondering the serial killer, the child molester, the brilliant psychopath, the man-monster - as cultural archetypes, then you might find a certain relief among the angels ... [Angels are] seen as providing ... temporary deliverance from a culture loaded with images of Gothic terror, (Edmundson 1997: 80-1).

King's representation of Jake Epping as a figuration of an angel in 11/22/63 presents the reluctant time-traveller as an epitome of the seraphs that, Edmundson suggests, offer relief from the various horrors that permeate American culture. King's representation of Jake as an emblem of the American fascination with seraphim figurations, however, also extends to an acknowledgement of their limited power to inhibit the Gothic aspects of the American cultural landscape. Edmundson's emphasization of the temporary nature of the deliverance that angels offer from the horrors of an increasingly Gothicized America is also reflected in 
$11 / 22 / 63$. The salvation of the majority of the Dunning siblings from the horror of their father's murderous rage within the confines of their family home by their guardian angel is not coded by King as permanent. Instead, Jake's actions represent a form of transitory respite, which King deliberately ends less than a decade later at Khe Sanh, a Gothicized topography located beyond Jake's jurisdiction as Harry Dunning's guardian angel. Consequently, it is the Vietnam War, rather than the Kennedy assassination of 22 November 1963, which King continues to frame as the spectre haunting his writing and, by extension, the collective cultural memory of the United States. In doing so, King joins other critics and commentators who consider whether the Vietnam War would have been very different had Kennedy lived to implement a peaceful outcome for the conflict, despite evidence to the contrary (see, for example, Kennedy's Quest for Victory: American Foreign Policy, 1961-1963 (Paterson 1989), creating a nostalgia for a Presidential rule that is coloured by his assassination, with his predilection for military intervention being erased from the cultural memory of the American public (Paterson 1989: 4-5).

As the novel progresses and Jake spends more time in the past, he makes larger changes to the historical timeline, and renders the sentience of time increasingly visible. Time does not want the changes to take place, and its active involvement in attempting to prevent the changing of the past can be seen both at various points in King's text. Time's resistance to change manifests on the body of Al Templeton, imprisoned by the death throes of terminal cancer, in a reactionary response to his attempts to prevent the American intervention in the Vietnam War. It resurfaces again at the climax of the novel, when Sadie ultimately becomes the sacrificial lamb whose death is figured as the counterbalance to Kennedy's survival. In saving Kennedy's life, the monumental impact of Jake's triumph over time also extends beyond the truncation of his romantic relationship with Sadie. Upon returning to the present, Jake discovers that his heroic actions have resulted in the present becoming an apocalyptic 
dystopia. As Al imagined, in surviving the assassination attempt, Kennedy did not send troops into Vietnam. However, the civil right reforms were not enacted in the US, and after the assassination of Martin Luther King, race riots across America took Kennedy's focus, which allowed the North Vietnamese to take control of Saigon. In 1960, twenty-four years to the day after Fat Man was dropped on Nagasaki, Wallace orders a nuclear bomb to be dropped on Hanoi, after North Vietnam refuses to surrender Saigon. The bombing is the catalyst for a proliferation of nuclear conflicts and earthquakes that rend the fabric of the planet - a product of the changes Jake has enacted by saving Kennedy in Dallas. Despite Jake beating time and ensuring Kennedy's survival, time responds to his victory by initiating a cataclysmic destruction of the American way of life, democratic freedom, and Earth's structural integrity. Whilst there is a focus on the temporal journey of Jake, and his efforts to change the timeline of American history, there is nevertheless an implicit critique of the politics of the US, and this can be seen in the fictional events following the survival of Kennedy. For example, in having Kennedy fail to establish the Civil rights movement, the novel questions Kennedy's role as an American saviour, reminding the reader that he voted against the Civil rights Act (John F Kennedy Presidential Library and Museum 2011). Thus, King takes part in the demythologising of the President, calling into question the accepted narrative of Kennedy's rule.

In The Alternate History: Refiguring Historical Time (2001), Hellekson critiques William Joseph Collins' taxonomy of alternate history by outlining three variant classifications of alternate history which privilege the break, instead of the position of the subject which informs Collins' method of classification. Through its predominant focus on the traveller, Jake Epping, and his motivations for attempting to re-write American history, 11/22/63 adheres to one of the four divisions of alternate history that Collins identifies: 'timetravel alteration, which has travellers moving from their present to their past to alter events' 
(Hellekson 2001: 5). The significance of Dealey Plaza, however, particularly in light of the causal relationship that King constructs between the shooting and the subsequent Vietnam War, means that 11/22/63 also represents an embodiment of the first of Hellekson's trinity of alternate history narratives: the nexus story. She describes this as 'an alternate history that focuses on a crucial point in history such as a battle or an assassination in which something different happens' (Hellekson 2001: 5). More specifically, King's novel epitomises a subset of the nexus story that Hellekson subsequently labels 'the time-travel-time-policing story'; narratives that 'occur around nexus points and generally feature some attempt to keep timelines clean (by time-travelling police charged with this duty)' (Hellekson 2001: 6). In King's text, fedora-sporting human agents referred to as 'the card men' maintain the structural integrity of the multiple time streams created by the various navigations of the temporal pathways between 2011 and 1958. They incrementally sacrifice their sanity to merge the multiple time streams produced as a consequence of travel in 'the bubble'. Al Templeton is guilty of a fundamental misconception of Kyle, the card man he encounters. Already suffering the psychologically damaging effects of merging and containing multiple time streams within the finite space of his own head, Kyle's mental stability progressively disintegrates, a transition signalled by the changing colours of the card tucked into the brim of his fedora. Initially mis-identified as an incoherent derelict by Templeton, it is only after Kyle's suicide, and his replacement by the less psychologically damaged figure of Zack Lang that the newly-inducted, lucid card man is able to coherently articulate the mechanics, and consequences, of Jake's time-travelling, and the nature of his profession as a watcher of the bubble:

My own sanity won't last much longer ... And the residual effects will stay with me forever. High suicide rate among our kind, Jake. Very high. Men and we are men, not aliens or supernatural beings ... aren't made to hold 
multiple reality-strings in their heads. It's not like using your imagination. It's not like that at all. We have training, of course, but you can still feel it eating into you. Like acid ... It's because the brain can't help trying to reconcile all those thin overlays of reality. The strings create multiple images of the future ... It gums up the machine. Eventually a point will come when the machine simply ... stops.

(King 2012: 697-8).

The cerebral decay inflicted upon the card men through their reconciliation of multiple time strings represents a neurological manifestation of time's presentation as a malevolent presence in King's text.

Jake does not see that the changes he is making to the past are so destructive to the future. However, he does notice what he calls 'harmonics', which are repeated throughout the novel. These are events where time appears to be trying to reinstate the timeline. King explains this structure by employing a musical analogy:

The multiple choices and possibilities of daily life are the music we dance to. They are like strings on a guitar, Strum them and you create a pleasing sound. A harmonic. But then start adding strings. Ten strings, a hundred strings, a thousand, a million. Because they multiply! (...) Sing high C in a voice that's loud enough and true enough and you can scatter fine crystal. Play the right harmonic notes through your stereo loud enough and you can shatter window glass. It follows (to me, at least) that if you put enough strings on time's instrument, you can shatter reality. (King 2012: 827).

In saving Kennedy's life, Jake triumphs over time, but the results are catastrophic. Saving Kennedy in 11/22/63 allows King to explicitly highlight the relationship between cause and 
effect that forms the basis of literary—and historical—counterfactual histories, asking the question 'What if Kennedy did not die at Dealey Plaza?', and offering an alternative present. As Hellekson writes, 'time's arrow is redirected and brings about a different outcome' (Hellekson 2001: 41). The concept of time's arrow is an important aspect of King's novel. Hellekson considers that time travel narratives frequently use either time's arrow, which posits 'time as linear' and 'is the metaphor implied in most historical writings' (Hellekson 2001: 36). In these narratives, there is a reliance on 'a sense of past, present, and future' (Hellekson 2001: 39), a typical narrative structure. King takes this structure, and complicates it, intimating a variant of the alternative history narrative through his use of the term 'harmonics'.

Harmonics intimates that all the events are perceived as a single and consistent universe. However, the presence of the card men shows that while this is the perception, it is not the reality of King's novel. Rather than there being a single temporality that is overwritten whenever someone re-enters the 'bubble', a new reality is created, one that the card men are always aware of, even if no-one else perceives its existence. After saving Kennedy, and discovering the dystopian future that he has engendered, Jake returns once again to 1958, to return events to their default setting. The end of the novel reveals that the novel is, in fact, a found manuscript that Jake wrote whilst in 1958 the final time, and which was buried there, before he returned to his original timeframe. This means that we are in the alternate presentand that Jake exists in a different temporality. This is suggestive of the concept of there being many parallel worlds, created as time travellers such as Jake and Al move between temporalities, changing events in the future. King's first person narrative calls into question the verisimilitude of Jake's version of events, blurring the boundaries between history and its fictional representation. In utilising this model, King borrows another of the categorisations of the alternate history championed by Collins. 
Ultimately, $11 / 22 / 63$ is a novel that cautions the reader against trying to change what has gone before. By presenting an America in which Kennedy survived, King shows that just as every action has a reaction, certain nexus points are fixed, and should not be altered, regardless of the hypothesised benefits of such a momentous change in history. Although Kennedy's survival of Oswald's assassination attempt is often regarded as the catalyst for a potentially idyllic alternate future, King instead presents it as the mechanism for a nightmarish dystopia, where progress towards racial equality remains uninitiated, and where war, poverty, and environmental disasters are commonplace. The dystopia is created as a consequence of the card men's struggle to reconcile the multiple reality-strings manufactured by Al and Jake's various time-travelling expeditions. The multiplicitous nature of the American landscape, haunted by various residual traces of the numerous time-streams that Jake traverses is mirrored in King's deliberate choice to create a novel that displays traces of a number of theoretical models of alternate history, and his subsequent attempt to reconcile them within a single narrative.

\section{References}

Adams, James Truslow (2001), The Epic of America, San Antonio, Texas: Simon Publications. 
Badley, Linda (1987), 'Love and Death in the American Car: Stephen King's Auto-Erotic

Horror', in Gary Hoppenstand and Ray B. Browne (eds), The Gothic World of Stephen King:

Landscape of Nightmares, Bowling Green, Ohio: Bowling Green Ohio State Popular Press, pp. 84-94.

Baker, Brian (2015), Contemporary Masculinities in Fiction, Film and Television, London: Bloomsbury.

Cullen, Jim (2003), The American Dream: A Short History of an Idea that Shaped a Nation, Oxford: Oxford University Press.

Edmundson, Mark (1997), Nightmare on Main Street: Angels, Sadomasochism and the Culture of Gothic, Cambridge, Massachusetts: Harvard University Press.

Fiedler, Leslie (1992), Love and Death in the American Novel, $3^{\text {rd }}$ ed., New York, Anchor Books.

George, Alice L. (2012), The Assassination of John F. Kennedy: Political Trauma and American Memory, London: Routledge.

Hellekson, Karen (2001), The Alternate History: Refiguring Historical Time, Kent, Ohio and London: The Kent State University Press.

Janicker, Rebecca (2015), The Literary Haunted House: Lovecraft, Matheson, King, and the Horror in Between, Jefferson, North Carolina: McFarland \& Co. 
John F Kennedy Presidential Library and Museum. (2018), John F. Kennedy's Pre-

Presidential Voting Record \& Stands on Issues (p. 5 of 9), Available at:

https://www.jfklibrary.org/Research/Research-Aids/Ready-Reference/JFK-Fast-

Facts/Voting-Record-and-Stands-on-Issues-Page-5.aspx, (accessed 26 September 2018).

Kennedy, John F. (1964), Public Papers of the Presidents of the United States: John F.

Kennedy, 1963, January 1 to November 22 1963, Washington, DC: United States Publishing Office.

King, Stephen (2006), Danse Macabre, London: Hodder.

(2007), Christine, London: Hodder.

(2012), 11/22/63, London: Hodder.

Manchester, William (2013), The Death of a President: November 20 - November 25, 1963, New York: Back Bay Books.

Merchant, Carolyn (2004), Reinventing Eden: The Fate of Nature in Western Culture, London: Routledge.

Nahin, Paul J. (1999) Time Machines: Time Travel in Physics, Metaphysics and Science Fiction, $2^{\text {nd }}$ ed., New York: Springer. 
Paterson, Thomas G (ed). (1989), Kennedy's Quest for Victory: American Foreign Policy, 1961-1963, Oxford: Oxford University Press.

Piereson, James. (2013) Camelot and the Cultural Revolution: How the Assassination of John F. Kennedy Shattered American Liberalism, $2^{\text {nd }}$ ed., New York: Encounter Books.

Rosenfield, Gavriel (2002), 'Why Do We Ask “What If?”, Reflections on the Function of Alternate History', History and Theory, 41:4, pp. 90-103.

Sturken, Marita (1997), 'Reenactment, Fantasy, and the Paranoia of History: Oliver Stone's Docudramas', History and Theory: Producing the Past: Making Histories Inside and Outside the Academy, 36:4, pp. 64-79.

'The Rabbit-Hole' (2016), Kevin Macdonald (dir.), 11/22/63, Series 1 Episode 1 (10 February, USA: Hulu). 


\section{Notes}

\footnotetext{
${ }^{1}$ The title, The Survival of a President, is an homage to The Death of a President, William Manchester's account of the Kennedy assassination and its aftermath. While King is critical of some aspects of Manchester's work, he still acknowledges its influence on his writing of 11/22/63: 'I was also deeply impressed - and moved, and shaken - by my rereading of
} William Manchester's Death of a President. He's dead wrong about some things ... but this massive work ... is closest in time to the assassination, written when most of the participants were still alive and ... his narrative of $11 / 22$ 's events is chilling and vivid, a Zapruder film in words' (King 2012: 1084-5).

${ }^{2}$ The title of Badley's essay is an homage to Leslie Fiedler's influential examination of American Literature Love and Death in the American Novel (1992). 